\title{
Efficacy of Quercus infectoria Oliv. Galls in the Management of Uterovaginal Prolapse: A Randomized Clinical Trial
}

\author{
Misba Naim ${ }^{1}$, Wajeeha Begum ${ }^{2}$ \\ ${ }^{1}$ PG, Dept of Ilmul Qabalat Wa Amraze Niswan, National Institute of Unani Medicine, Bengaluru \\ ${ }^{2}$ Professor and HoD, Dept of Ilmul Qabalat Wa Amraze Niswan, National Institute of Unani Medicine, Bengaluru
}

\begin{abstract}
Aim: To evaluate the efficacy of Quercus infectoria Oliv. galls in first and second degree uterovaginal prolapse and to assess the improvement in the quality of life of women. Methodology- test group $(n=30)$ was given powder of Quercus infctoria Olivier galls for sitz bath and control group $(n=30)$ was given placebo. Both groups were advised Kegel's exercise in addition. Results: Significant results obtained. Conclusion- Galls of Quercus infectoria are effective in improving the uterovaginal prolapse as well as quality of life of women. It can serve as an alternative treatment in the management of uterovaginal prolapse.
\end{abstract}

Keywords: Uterovaginal prolapse, Quercus infectoria, kegel's exercise, women

\section{Introduction}

Uterovaginal prolapse is a common and distressing condition. ${ }^{1}$ It refers to loss of support to the uterus, bladder and bowel leading to their descent from the normal anatomic position towards or through the vaginal opening. ${ }^{2}$ One-third of all hysterectomies in postmenopausal women and $81 \%$ of vaginal hysterectomies (representing about $16 \%$ of all hysterectomies) are performed for prolapse. ${ }^{1}$ Globally up to half of all parous women have some degree of clinical prolapse. In addition to mechanical discomfort, it may negatively affect sexuality, body image and quality of life and is one of the most common reasons for gynecological surgery peaking in upper midlife. ${ }^{3}$ Multiparty, prolonged labor, poorly supervised and unsupervised deliveries are significant determinants. In conventional system of medicine, treatment is pessary insertion in early stages and surgery in later stages which has got its own side effects and complications. ${ }^{4}$ If the condition affects the older age group women, who have completed their families, the treatment is usually definite surgery, but the issue arises when younger women who are less than 40 years of age and either they have yet to complete their family or they do not want to resort to hysterectomy so early in their life. ${ }^{5}$

According to literature of Unani system of medicine, uterovaginal prolapse is a condition in which the uterus descends below into the vagina or outside the introitus from its normal level. ${ }^{6}$ It is caused by the accumulation of viscous humor (ghaleez balgham) in the ligaments of uterus. ${ }^{7,8}$ It usually occurs in old women having excessive fluid in her body. ${ }^{6}$

This has been treated by various drugs having qabiz (astringent), jazib (absorbent), mujaffif (dessicant) and muqawwie rehm (uterine tonic) properties mentioned in classical unani books. ${ }^{6,7,8}$ Therefore it is the need of present era to evaluate the efficacy of unani drugs for uterovaginal prolapse on the scientific basis and modern parameters. Keeping in mind of the present scenario as well as after thorough review of unani literature, $Q$. infectori Oliv. ${ }^{9,10,11,12}$ has been selected to evaluate its efficacy in the management of first and second degree uterovaginal prolapse.

The aim of the study was to evaluate the efficacy of $Q$. infectoria galls in uterovaginal prolapse and to assess the improvement in the quality of life of women with uterovaginal prolapse.

\section{Material and Methods}

This randomized single blind placebo controlled study was conducted in the Dept. of Ilmul Qabalat Wa Amraze Niswan, National Institute of Unani Medicine Hospital, Bengaluru, during the year 2014-15. Keeping in consideration the availability of patients and limited resources, 60 patients were recruited for the present study. Patients were allocated randomly to either of the test $(n=30)$ or control group $(n=30)$. Randomization was done by computer generated simple randomization table. Prior to initiation of the study, the protocol and informed consent were reviewed and approved by institutional ethical committee, NIUM, Bengaluru, with IEC No: NIUM/IEC/2014-15/009/ANQ/01 dt.16/04/2015.

Data was collected by history, clinical examination and laboratory investigations.

\section{Inclusion criteria}

Married women in the age group 30-60 years, with first or second degree uterovaginal prolapse and willing to participate in the study.

\section{Exclusion criteria}

Procidentia, congenital elongation of cervix, cervical fibroid, polyp, chronic inversion of uterus, pregnant, lactating women, systemic illnesses and malignancy.

Patients fulfilling inclusion criteria were enrolled in the study after obtaining informed consent. In each patient a detailed history was evaluated with basic information. Following thorough evaluation of history and clinical 


\section{International Journal of Science and Research (IJSR) \\ ISSN (Online): 2319-7064}

Index Copernicus Value (2015): 78.96 | Impact Factor (2015): 6.391

examination, patients were subjected to baseline investigations CBP, ESR, CUE, HIV, VDRL, LFT, RFT, RBS, Pap smear, USG pelvis.

\section{Intervention}

Test group $(\mathrm{n}=30)$ received $Q$. infectoria Oliv. galls for 8 weeks. Galls were cleaned, pounded, sieved $\&$ mixed well to make homogenous powder and was given. Patient was asked to make decoction of $20 \mathrm{gm}$ powder in 1 litre of water and then 4 litres water added to for sitz bath (15 minutes once daily) $)^{9,10,11,12}$. For placebo group- common salt, 10 gram in 5 litres of water was used as sitz bath. Biochemical estimations were repeated after the completion of trial.

Effectiveness of trial drug was assessed by subjective and objective parameters. Subjective parameters included mass per vaginum, urinary incontinence, backache and lower abdominal discomfort assessed at baseline, fortnightly for eight weeks during treatment and for one month after treatment once in 15 days. For assessment of mass per vaginum, Baden Halfway grading system was used. Urinary incontinence was assessed by provocative stress test; low backache and abdominal discomfort were assessed by Visual Analogue Scale (VAS). Objective parameters included Pelvic Floor Distress Inventory Questionnaire (PFDIQ-20) and Pelvic Floor Impact Questionnaire (PFIQ-7). ${ }^{13}$

PFDIQ assess symptom distress in women with pelvic floor disorders. The short form version of the PFDIQ has a total of 20 questions and 3 scales (UDI-6, POPD-6, and CRADI-8) were used.

PFIQ evaluate the impact of bladder, bowel, and vaginal symptoms on a woman's daily activities, relationships and emotions. The short form version of the PFIQ has a total of 21 questions and 3 scales (UIQ-7, POPIQ-7, and CRAIQ-7).

\section{Statistical Analysis}

The Statistical software namely SAS 9.2, SPSS 15.0, Stata 10.1, Med Calc 9.0.1, Systat 12.0 and R environment ver.2.11.1 were used for the analysis of the data. Student $t$ test (two tailed, independent) has been used to find the significance of study parameters on continuous scale between two groups (Inter group analysis) on metric parameters. Chi-square/ Fisher Exact test has been used to find the significance of study parameters on categorical scale between two or more groups. Non parametric setting was used for Qualitative data analysis. Significance was assessed at $5 \%$ level of significance. ${ }^{14,15,16 .}$

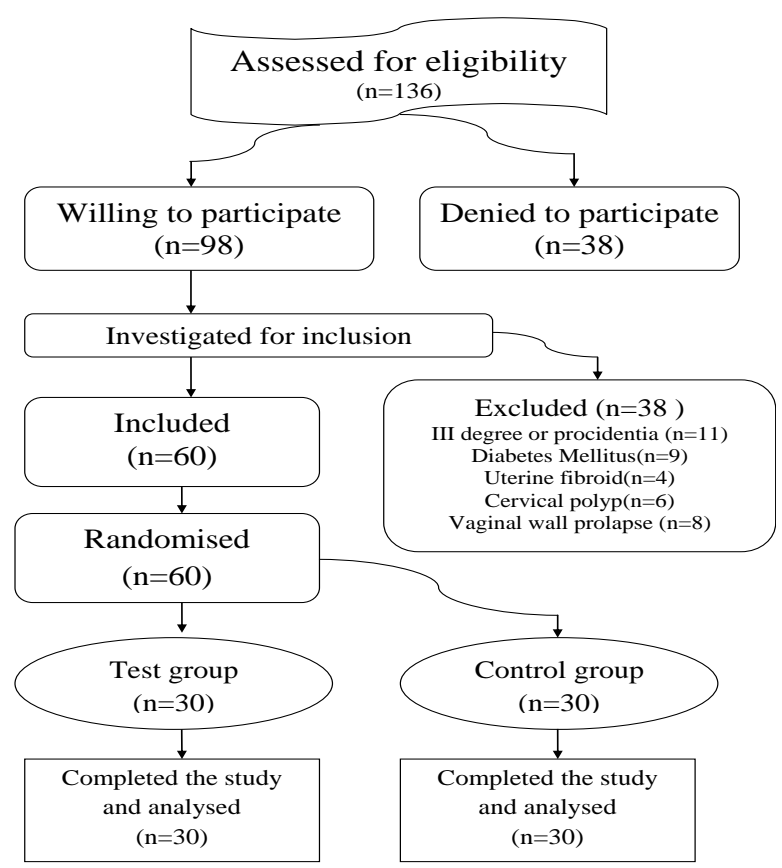

Figure 1: Flowchart of the study.

\section{Results}

Table 1: Baseline demographic data of UVP patients in test and control group.

\begin{tabular}{|c|c|c|c|c|c|}
\hline \multirow{2}{*}{ Demographic data } & \multicolumn{2}{|c|}{$\begin{array}{l}\text { Test group } \\
(\mathrm{n}=30)\end{array}$} & \multicolumn{2}{|c|}{$\begin{array}{c}\text { Control group } \\
(\mathrm{n}=30)\end{array}$} & \multirow[t]{2}{*}{ P value } \\
\hline & No & $\%$ & No & $\%$ & \\
\hline $\begin{array}{l}\text { Age (years) } \\
30-40 \\
40-50 \\
50-60\end{array}$ & $\begin{array}{l}17 \\
9 \\
4\end{array}$ & $\begin{array}{c}56.7 \\
30 \\
13.3\end{array}$ & $\begin{array}{c}22 \\
6 \\
2\end{array}$ & $\begin{array}{c}73.3 \\
20 \\
6.7\end{array}$ & 0.09 \\
\hline Mean \pm SD & \multicolumn{2}{|c|}{$41.93 \pm 8.04$} & \multicolumn{2}{|c|}{$38.53 \pm 7.21$} & \\
\hline $\begin{array}{l}\text { Attained menopause } \\
\text { No } \\
\text { Yes }\end{array}$ & $\begin{array}{l}21 \\
9\end{array}$ & $\begin{array}{c}70 \\
30\end{array}$ & $\begin{array}{l}24 \\
6\end{array}$ & $\begin{array}{c}80 \\
20 \\
\end{array}$ & 0.371 \\
\hline $\begin{array}{l}\frac{\text { BMI }}{<18.5} \\
18.5-25 \\
25-30 \\
>30\end{array}$ & $\begin{array}{l}01 \\
20 \\
06 \\
03\end{array}$ & $\begin{array}{c}3.3 \\
66.7 \\
20 \\
10\end{array}$ & $\begin{array}{c}0 \\
23 \\
06 \\
01\end{array}$ & $\begin{array}{c}0 \\
76.7 \\
20 \\
3.3\end{array}$ & 0.577 \\
\hline Mean \pm SD & \multicolumn{2}{|c|}{$24.13 \pm 3.66$} & \multicolumn{2}{|c|}{$23.66 \pm 2.85$} & \\
\hline $\begin{array}{l}\text { Temperament } \\
\text { Damvi } \\
\text { Balghami } \\
\text { Safravi } \\
\text { Saudavi }\end{array}$ & $\begin{array}{c}07 \\
22 \\
01 \\
0\end{array}$ & $\begin{array}{c}23.3 \\
73.3 \\
3.3 \\
0\end{array}$ & $\begin{array}{c}03 \\
23 \\
04 \\
0\end{array}$ & $\begin{array}{c}10 \\
76.7 \\
13.3 \\
0\end{array}$ & 0.194 \\
\hline $\begin{array}{l}\text { SES } \\
\text { Lower middle } \\
\text { Upper lower } \\
\text { Upper middle } \\
\text { Upper }\end{array}$ & $\begin{array}{l}20 \\
05 \\
04 \\
01\end{array}$ & $\begin{array}{c}66.7 \\
16.7 \\
13.3 \\
3.3\end{array}$ & $\begin{array}{c}17 \\
10 \\
03 \\
0\end{array}$ & $\begin{array}{c}56.7 \\
33.3 \\
10 \\
0\end{array}$ & $0.347 *$ \\
\hline $\begin{array}{l}\text { Education } \\
\text { Illiterate } \\
\text { Primary School } \\
\text { Middle School } \\
\text { High School } \\
\text { Intermediate/UG/PG }\end{array}$ & $\begin{array}{c}5 \\
11 \\
4 \\
7 \\
3\end{array}$ & $\begin{array}{c}16.7 \\
36.7 \\
13.3 \\
23.3 \\
10\end{array}$ & $\begin{array}{c}6 \\
13 \\
8 \\
1 \\
2\end{array}$ & $\begin{array}{c}20 \\
43.3 \\
26.7 \\
3.3 \\
6.7\end{array}$ & 0.209 \\
\hline
\end{tabular}




\section{International Journal of Science and Research (IJSR) \\ ISSN (Online): 2319-7064}

Index Copernicus Value (2015): 78.96 | Impact Factor (2015): 6.391

Table 2: Obstetrics risk factors in UVP patients.

\begin{tabular}{|c|c|c|c|}
\hline Obstetric events & Test group & Control group & P value \\
\hline Parity & & & \\
1 & $1(3.3 \%)$ & $2(6.67 \%)$ & \\
2 & $2(6.67 \%)$ & $5(16.67 \%)$ & 0.388 \\
3 & $9(30 \%)$ & $11(36.7 \%)$ & \\
4 and above & $18(60 \%)$ & $12(40 \%)$ & \\
\hline Nature of delivery & & & \\
FTNVD & $29(96.7 \%)$ & $27(90 \%)$ & 0.612 \\
LSCS & $1(3.3 \%)$ & $3(10 \%)$ & \\
\hline Place of delivery & & & \\
Home & $20(66.67 \%)$ & $19(63.3 \%)$ & 0.787 \\
Hospital & $10(33.3 \%)$ & $11(36.7 \%)$ & \\
\hline Average weight of & & & \\
babies at birth (in kg) & & & \\
$<2.7$ & $4(13.3 \%)$ & $1(3.3 \%)$ & \\
$2.7-3$ & $25(83.3 \%)$ & $29(96.7 \%)$ & 0.195 \\
3 and above & $1(3.3 \%)$ & $0(0 \%)$ & \\
\hline
\end{tabular}

Table 3: Primary and secondary outcome in patients of both groups.

\begin{tabular}{|c|c|c|c|c|c|c|c|}
\hline \multirow{2}{*}{$\begin{array}{c}\text { Outcome } \\
\text { Measures }\end{array}$} & \multicolumn{2}{c|}{$\begin{array}{c}\text { Test group } \\
(n=30)\end{array}$} & \multicolumn{2}{c|}{$\begin{array}{c}\text { Control group } \\
(n=30)\end{array}$} & \multicolumn{2}{c|}{ P value } \\
\cline { 2 - 8 } & $B T$ & $A T$ & $B T$ & $A T$ & $T G$ & $C G$ \\
\hline Primary & MPV & $1.6 \pm$ & $0.66 \pm$ & $1.33 \pm$ & $0.53 \pm$ & 0.0001 & 0.0001 \\
& & 0.56 & 0.47 & 0.47 & 0.5 & & \\
\cline { 2 - 9 } & $\mathrm{UI}$ & $0.6 \pm$ & $0.26 \pm$ & $0.46 \pm$ & $0.3 \pm$ & 0.001 & 0.001 \\
& & 0.5 & 0.44 & 0.5 & 0.46 & & \\
\cline { 2 - 9 } & LBA & $2.13 \pm$ & $0.93 \pm$ & $2.23 \pm$ & $1.03 \pm$ & 0.0001 & 0.0001 \\
& & 0.43 & 0.44 & 0.43 & 0.55 & & \\
\cline { 2 - 8 } & LAD & $1.4 \pm$ & $0.46 \pm$ & $1.36 \pm$ & $0.36 \pm$ & 0.0001 & 0.0001 \\
& & 0.56 & 0.5 & 0.49 & 0.49 & & \\
\hline Secondary & PDI-Q & $98.97 \pm$ & $61.03 \pm$ & $87.03 \pm$ & $57.33 \pm$ & 0.0001 & 0.0001 \\
Outcome & & 28 & 20.1 & 20 & 17 & & \\
\cline { 2 - 8 } & PFI-Q & $128.7 \pm$ & $71.77 \pm$ & $121.57 \pm$ & $65.81 \pm$ & 0.0001 & 0.0001 \\
& & 38 & 33.9 & 33 & 23 & & \\
\hline
\end{tabular}

\section{Discussion}

There was no significant difference between the groups concerning baseline characteristics with $p=>0.05$ (Table 1). Maximum numbers of patients in our study were of age group $30-40$ yrs $(65 \%)$ followed by $41-50$ years $(25 \%)$. This is similar to finding of Kashyap et al, that majority of women with symptoms of pelvic organ prolapse was in the age group of 31-40 years. Developing symptoms at such young age could be attributed to the customs of early marriage and early and repeated pregnancies in India without proper spacing between deliveries. ${ }^{17}$

Balghami temperament was found in $22(73.3 \%)$ and 23 $(76.7 \%)$ patients in the test and control group respectively This finding correlates with the opinions of unani physicians who quoted that prolapse occurs due to accumulation of viscous balgham and thus the dominant humor in these patients is humor balgham. The present study shows that in test group, $21(70 \%)$ patients whereas in control group, 24 (80\%) patients have not attained menopause. The contradictory result is because of strict inclusion criteria (inclusion of first and second degree uterovaginal prolapse which is less common in menopausal group) as stage of prolapse increases with the age.

Kuppuswamy's scale was used to assess the socioeconomic status. It was comparable in two groups and was found statistically not significant. ${ }^{18}$ Thapa et al. reported that $82 \%$ of the patients with uterovaginal prolapse were illiterate in their study. Similar results were reported by the study of Pradhan (2007). Results reveal that $85 \%$ of respondents of uterine prolapse were illiterate. ${ }^{19}$ Other studies also supports our findings which shows that the prevalence of uterine prolapse is significantly high among illiterate women than the literates. The incidence of uterovaginal prolapse increases with parity. ${ }^{19,20,21}$ Repeated trauma to the pelvic floor muscles due to repeated pregnancies is the major factor for developing prolapse. ${ }^{22}$ In our study, mean parity was $3.9 \pm 1.29$ and $3.36 \pm 1.35$ in test group and control group respectively with $P=0.124$ which is in consistent with the finding of many studies like Kim et al $2(3.12 \pm 1.15)^{23}$, Kashyap et al $(3.3 \pm 1.4 \text { and } 3.0 \pm 1.1)^{24}$ and Roovers et al $(2.5 \pm 1.2$ and $2.9 \pm 1.1) .{ }^{25}$ Maximum patients in the study have history of normal vaginal deliveries which is considered as a major risk factor for the development of uterovaginal prolapse. $55(91.7 \%)$ patients has average birth weight of $\geq$ $2.7 \mathrm{~kg}$ at time of deliveries. (Table 2) This supports the unani literature where it is mentioned that big baby is one of the obstetric risk factor of the uterovaginal prolapse. ${ }^{6,26}$

Before treatment the mean score of mass per vaginum was $1.6 \pm 0.56$ and $1.33 \pm 0.47$ in test and control group respectively. After intervention it was reduced significantly to $0.66 \pm 0.47$ and $0.53 \pm 0.5$ in test and control group with $\mathrm{p}$ value $<0.0001$ considered highly significant. $Q$. infectoria galls had strong astringent, absorbent, dessicant and uterotonic property due to the presence of chemical constituents like tannins, phenols, flavonoids etc. ${ }^{27,28,29}$ This may strengthens the uterine ligaments and other loose pelvic supports which helped the uterus to revert back to its position. Mean \pm SD of urinary incontinence score was reduced to $0.26 \pm 0.44$ and $0.3 \pm 0.46$ from $0.6 \pm 0.5$ and $0.46 \pm 0.5$ in test and control group respectively with $\mathrm{p}$ value $<0.0001$ considered statistically significant. Mean score of VAS for LBA drops from $2.13 \pm 0.43$ and $2.23 \pm 0.43$ to $0.93 \pm 0.44$ and $1.03 \pm 0.55$ in test and control group respectively with $\mathrm{p}$ value $<0.0001$. Statistically significant result was seen in lower abdominal discomfort with score $1.4 \pm 0.56$ and $1.36 \pm 0.49$ before treatment to $0.46 \pm 0.5$ and $0.36 \pm 0.49$ after treatment in test and control group respectively.

PDI-Q score was reduced from $98.97 \pm 28$ to $61.03 \pm 20.1$ in test with $p$ value $<0.0001$. PFI-Q score was $128.7 \pm 38$ in test group at baseline which reduced to $71.77 \pm 33.9$ in after treatment with $\mathrm{p}<0.001$. Improvement in women's QoL from baseline to 12 weeks reached significance $(p<0.001)$ in test group. (Table 3)

This is the first randomized single-blind study on Quercus infectoria in management of uterovaginal prolapse. It also included the use of several widely used validated instruments for the evaluation of UVP and health related quality of life and the ability to compare results for each of these questionnaires in the same population of women. Our limitations are single-blind, small sample size and followup-assessment took place only once post-intervention. Kegel's exercise was also advised with intervention in both groups, which have its own potential effect in pelvic floor disorders.

\section{Volume 6 Issue 7, July 2017 www.ijsr.net}




\section{International Journal of Science and Research (IJSR) \\ ISSN (Online): 2319-7064}

Index Copernicus Value (2015): 78.96 | Impact Factor (2015): 6.391

\section{Conclusion}

Hence, in the present study, it is hypothesized that the $Q$. infectoria galls in addition with kegel's exercise is effective and safe in subjective improvement of UVP symptoms and thereby improving HRQoL. This demonstrates that sitz bath of these galls can be an alternative herbal treatment for alleviating symptoms of UVP. The study validates the claim of Unani scholars that $Q$. infectoria Oliv. galls are effective in management of UVP because of its strong astringent activity. Specific mechanism of action is not known but it can be hypothesized that galls contains tannin which constricts the uterine ligaments, absorb the excessive fluids and provide strength to pelvic floor muscles.

\section{Future Scope}

Galls of $Q$. infectoria Oliv. are effective and safe for subjective improvement and thereby improving quality of life in women with UVP. Further, double-blind with extending the time of intervention in larger sample size, phase III trials are recommended. Further studies are needed to find the exact mechanism of action of $Q$. infectoria galls in UVP.

\section{References}

[1] PD Patel, KV Amrute, GH Badlani, "Pathophysiology of pelvic organ prolapse and stress urinary incontinence," Indian Journal of Urology. XXII(4), pp. 310-316, 2006.

[2] I. Giarenis and D. Robinson, "Prevention and management of pelvic organ prolapse," F1000Prime Reports 2014.(doi:10.12703/P6-77)

[3] M Gyhagen, M Bullarbo, TF Nielsen, I Milsom, "Prevalence and risk factors for pelvic organ prolapse 20 years after childbirth: a national cohort study in singleton primiparae after vaginal or caesarean delivery", BJOG, 120, pp. 152-160, 2013.

[4] BS Ransom, Practical Strategies in Obstetrics and Gynaecology; W.B.Saunders company, 2000.

[5] M. Mansoor, "Uterovaginal Prolapse: use of autologous rectus sheath to repair,” Professional Med J, XXI(5), pp. 1059-1062, 2014.

[6] MA Khan, Akseer Azam (Urdu trans. by Kabeeruddin M). New Delhi: Idarae Kitabul Shifa, 2011.

[7] I. Jurjani, Zakheerae Khawarzam Shahi. (Urdu trans. by Khan AH) Vol VI. New Delhi: Idarae Kitabul Shifa, 2010.

[8] ABA. Majoosi, Kamilus Sana (Urdu trans. by Kantoori GH). New Delhi: Idarae Kitabul Shifa, 2010.

[9] J. Ghulam, Mukhzinul Ilaj, Idarae Kitabul Shifa, New Delhi, 2005.

[10]I. Betar, Al Jamiul Mufradat Al-Advia Wal-Aghzia. Vol- III, New Delhi, CCRUM, 1999.

[11] NM. Ghani, Khazainul Advia, Idarae Kitabul Shifa New Delhi, YNM.

[12] AK. Nadkarni, Indian Materia Medica, Popular Prakashan Pvt Ltd, Mumbai 2010.

[13] MD Barber, MD Walters, RC Bump, "Short forms of two condition-specific quality of life questionnaires for women with pelvic floor disorders (PFDI-20 and PFIQ-
7)," American journal of Obstetrics and Gynecology, 193, pp. 103-13,2005.

[14]RH. Riffenburg, Statistics in Medicine. $2^{\text {nd }}$ ed. Academic Press, 2005.

[15] S. Rao, J. Richard, An Introduction to Biostatistics: A manual for students in Health Sciences. $4^{\text {th }}$ ed.: Prentice Hall of India. New Delhi 2006.

[16] KP. Suresh, S. Chandrasekhar, "Sample Size estimation and Power analysis for Clinical research studies," J. Human Rep. Sciences, V (1), pp. 7-13, 2012.

[17] R. Kashyap, A. Singh, V. Jain. "Bother and quality of life among symptomatic versus asymptomatic women with stage I-III pelvic organ prolapse," The New Indian Journal of OBGYN, III (1), pp. 29-36, 2016. (doi:10.2127/ongyn.2016.3.1.6)

[18]D. Paneru, Research report-Uterine prolapse in Doti district of Nepal, Nepal Health Research Council, 2010.

[19]B. Thapa, G. Rana, S. Gurung, "Contributing factors of utero vaginal prolapse among women attending in Bharatpur Hospital," Journal of Chitwan Medical College, IV (9), pp. 38-42, 2014.

[20] O. Birge, S. Tunc, S. Ozyegin, I. Kayar, U. Akgor, MM. Erkan et al. "The Relationship of Uterine Prolapse and Epidemiological factors in a part of Tropical Africa," Int. J. Dev Res, V (12), pp. 6339-6343, 2015

[21]HP. Dietz, "Prolapse worsens with age, doesn't it?," Australian and New Zealand Journal of Obstetrics and Gynaecology, 48, pp. 587-91.2008.

[22] P. Patil, A. Patil, "Evaluation of pelvic organ prolapse in Indian females," Journal of Evolution of Medical and Dental Sciences; II (40), pp. 7612-7620, 2013.

[23] CM. Kim, MJ. Jeon, DJ Chung, SK Kim, JW Kim, SW Bai. "Risk factors for pelvic organ prolapse," International Journal of Gynecology and Obstetrics, 98, pp. 248-51, 2007.

[24] R. Kashyap, A. Singh, V. Jain, "Bother and quality of life among symptomatic versus asymptomatic women with stage I-III pelvic organ prolapse," The New Indian Journal of OBGYN, III(1), pp. 29-36, 2016. (doi:10.2127/ongyn.2016.3.1.6)

[25] JP. Roovers, CH. Vaart, JG. Bom, JHS. Leeuwen, PC. Scholten, APM. Heintz, "A randomized controlled trial comparing abdominal and vaginal prolapse surgery: Effects on urogenital function," BJOG , 111, pp. 50-56, 2004.

[26] S. Ibn, Al Qanoon Fil Tib (Urdu trans. by Kantoori GH),Idarae Kitab-us-Shifa, New Delhi 2010.

[27] TE Wallis. Textbook of Pharmacognosy ( $5^{\text {th }}$ ed.)CBS publisher and distributors, New Delhi, 2015.

[28] WC. Evans, Trease and Evans Pharmacognosy. (15th ed.), Rajkamal Electric Press, New Delhi, pp. 472,477, 2002.

[29] Anonymous. The Unani Pharmacopoeia of India. II (1), CCRUM, New Delhi, 2007.

\section{Author profile}

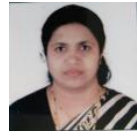

Wajeeha Begum received the BUMS and BAMS integrated medicine and MD OBG degree (1988) from Bengaluru University and NTR University of Health Sciences. She has the experience of 15 years in academic and she has guided more than 25 PG scholars, published up to 70 papers in peer reviewed journals. She has been awarded 


\section{International Journal of Science and Research (IJSR) \\ ISSN (Online): 2319-7064}

Index Copernicus Value (2015): 78.96 | Impact Factor (2015): 6.391

many times for excellence in health services and academic activities.

Misba Naim received BUMS degree from Aligarh

Muslim University in 2014 and is currently pursuing PG degree from Dept of OBG in National Institute of

Unani Medicine, Bengaluru. 